\title{
Single Unit Analysis of the Human Ventral Thalamic Nuclear Group: Correlation of Thalamic "Tremor Cells" with the 3-6 Hz Component of Parkinsonian Tremor
}

\author{
F. A. Lenz, ${ }^{1}$ R. R. Tasker, ${ }^{1}$ H. C. Kwan, ${ }^{4}$ S. Schnider, ${ }^{5, a}$ R. Kwong, ${ }^{5}$ Y. Murayama, ${ }^{1}$ J. O. Dostrovsky, ${ }^{4}$ and \\ J. T. Murphy ${ }^{2,3}$ \\ Divisions of ${ }^{1}$ Neurosurgery, ${ }^{2}$ Neurology, and ${ }^{3}$ Clinical Neurophysiology, Toronto General Hospital, Toronto, M5G 2C4 \\ Canada, and Departments of ${ }^{4}$ Physiology and ${ }^{5}$ Electrical Engineering, University of Toronto, Toronto, M5S $1 \mathrm{~A} 1 \mathrm{Canada}$
}

\begin{abstract}
Although cells firing at tremor frequency, called "tremor cells" (Guiot et al., 1962), have often been recorded in the thalamus of parkinsonian patients, the extent of correlation between these spike trains and tremor has rarely been assessed quantitatively. This paper describes spectral cross-correlation functions calculated between the activity of "tremor cells" and electromyogram (EMG) signals recorded from several muscles in the contralateral arm. The power occurring in the spike train at tremor frequency was described in absolute terms by the spike autopower, and in relation to the average for all spectral components by the spike autopower signal-to-noise ratio (spike autopower SNR). The probability of significant cross-correlation between the thalamic spike train and EMG at tremor frequency was assessed by the coherence at tremor frequency. Autopower spectra of the activity of many of these cells exhibited a concentration of power at tremor frequency, indicated by spike autopower SNRs as high as 18. Of the EMG signals studied, signals recorded from finger flexors were most often significantly correlated with the thalamic spike train, as assessed by the coherence at tremor frequency. Significant correlation between the thalamic spike train and finger flexor EMG activity was found in $34 \%$ of cells analyzed. Tremor frequency coherence was significantly correlated with tremor frequency spike autopower $(r=0.46, p<0.0001)$ and spike autopower SNR $(r=0.533, p<0.0001)$. The proportion of cells with a spike autopower SNR greater than 2 that were significantly correlated with finger flexor EMG activity was greater than that of cells with a spike autopower SNR of less than 2 ( $p<0.001$; chi-square). Therefore, cells exhibiting a large amount of power at tremor frequency were those best correlated with EMG activity during tremor. Some of these cells may be involved in the generation of tremor.
\end{abstract}

\footnotetext{
Received Feb. 4, 1987; revised July 21, 1987; accepted July 21, 1987.

We wish to thank Hoi Nguyen-Huu for writing the programs used in this study and Mary Teofilo and Allan Suran for technical assistance. This work was supported by grants from the PSI Foundation, Toronto, Canada and MRC (Canada).

F.A.L. was an MRC (Canada) Fellow and a Schering Scholar of the American College of Surgeons.

Correspondence should be addressed to Dr. Frederick A. Lenz, \% Division of Neurosurgery, 14-216, Eaton North Wing, Toronto General Hospital, 200 Elizabeth Street, Toronto, Ontario, M5S 2C4 Canada.

a Present address: Scientific Staff, Bell Northern Research, Ottawa, Ontario, Canada.
}

Copyright (C) 1988 Society for Neuroscience $0270-6474 / 88 / 030754-11 \$ 02.00 / 0$
In 1962, Guiot, Hardy, and Albe-Fessard first reported the presence of subcortical neurons, called "tremor cells," which fired in bursts at frequencies similar to that of tremor. Since this initial report, the presence of tremor cells has been confirmed repeatedly in the ventral nuclear group of human thalamus, as well as in other thalamic nuclei, pallidum, putamen, caudate, and motor cortex (reviewed by Ohye, 1982; Tasker et al., 1982). However, the dramatic relief of tremor produced by lesions in the ventral tier of lateral thalamic nuclci (Scott et al., 1970; Hassler et al., 1979; Kelly and Gillingham, 1980; Tasker et al., 1983) has focused attention on the relationship between tremor and tremor cells in this particular region (Jasper and Bertrand, 1966; Ohye and Albe-Fessard, 1978; Lamarre and Joffroy, 1979).

Since a lesion that destroyed tremor cells abolished tremor, it was logical to propose that parkinsonian tremor might be driven by direct transmission of tremor cell activity to the periphery (Jasper and Bertrand, 1966; Ohye and Albe-Fessard, 1978; Lamarre and Joffroy, 1979). A corollary of this hypothesis is that the thalamic tremor cell activity and tremor are linearly related. On the basis of visual assessment, the 2 signals have bcen reported to be correlated by some investigators (Guiot et al., 1962; Gaze et al., 1964; Hardy et al., 1964; Albe-Fessard et al., 1966; Jasper and Bertrand, 1966; Lucking et al., 1972; Raeva, 1972; Umbach, 1972) and to be uncorrelated by others (Bertrand et al., 1969, 1973; Donaldson, 1973; Velasco and Molina-Negro, 1973). Studies employing objective means of assessment clearly identify a strong tremor-frequency component in the activity of tremor cells, although the cross-correlation function between the tremor cell spike train and tremor was not calculated (Ohye et al., 1974; Ohye and Albe-Fessard, 1978; Lamarre and Joffroy, 1979). The cross-correlation functions between thalamic slow wave (Alberts et al., 1965) or thalamic single-unit (Crowell et al., 1968) signals and tremor suggested that neither thalamic signal was correlated with tremor, although statistical testing was not carried out.

In the present study, the degree of correlation between the activity of thalamic tremor cells and tremor was determined by statistical analysis of single unit and electromyogram (EMG) signals. The spike train was converted to an equivalent analog signal (French and Holden, 1971a), which was cross-correlated with EMG activity using frequency domain analysis, including evaluation of the coherence function as an estimator of the probability of correlation (Cox and Lewis, 1966, 1970; Jenkins and Watts, 1968; Benignus, 1969; Bendat and Piersol, 1971). The results demonstrate a population of thalamic tremor cells 
that are correlated with EMG activity during tremor to a statistically significant degree.

Preliminary results have been published in abstract form (Lenz et al., 1985, 1986b).

\section{Materials and Methods}

The results described in the present report were collected over a period of 4 years in 7 patients with parkinsonian tremor. These patients had a mean age of 66 years and a chief complaint of unilateral tremor, refractory to medical therapy. The protocol used in these studies conforms to the principles for research involving human beings endorsed by the Society for Neuroscience and was reviewed and approved by the Human Experimentation Committee at the University of Toronto.

Operating and recording techniques. Thalamotomy was performed as a 2-stage procedure employing the Leksell frame (Tasker et al., 1982; Lenz et al., 1987). First, the 3-dimensional frame coordinates of the anterior and posterior commissures were measured with positive-contrast ventriculography, as previously described (Tasker et al., 1982). A computer program (Hawrylyshyn et al., 1976) then shrank or expanded the sagittal sections of the Schaltenhrand and Bailey atlas (1959) to produce a set of maps conforming to the patients' intercommissural distance. During the second stage, physiologic corroboration of the stereotaxic target was performed under local anesthetic using single unit recording with a high-impedance microelectrode.

The platinum-iridium microelectrode used was electrolytically etched to a tip of 3-4 $\mu \mathrm{m}$ and coated with solder glass to give an impedance of approximately 2-4 M $\Omega$ at $1000 \mathrm{~Hz}$. The distal $1 \mathrm{~cm}$ of this electrode was then sheared off and inserted into the end of a 26-gauge, insulated, stainless steel tube. The microclectrode was then fixed to a modificd hydraulic microdrive (David Kopf Instruments, CA), which incorporated a high-impedance preamplifier. At operation, a thin-walled stainless steel guide tube with rigid obturator was introduced to a point just anterior and dorsal to the ventral thalamic nuclear group. The obturator was then replaced with the microelectrode-preamplifier assembly and the microelectrode progressively advanced, using the hydraulic microdrive. The microelectrode signal was recorded and filtered using standard techniques $(-6 \mathrm{~dB}$ at 300 and $10,000 \mathrm{~Hz})$. Isolated single units were easily recorded and held using this system, despite the lack of fixation of the cranium.

Microelectrode trajectories targeted the ventrocaudal, ventralis intermedius, and ventralis oralis posterior nuclei of the thalamus in the 14-15 mm lateral plane, as located on the computer-generated map described above. If cells responding to somatosensory stimulation (sensory cells) or tremor cells were not located along these trajectories, then additional trajectories were made lateral and/or medial to the plane of the initial trajectory until sensory cells or tremor cells were found. All electrode trajectories lay in virtually parasagittal planes approaching the intercommissural line at angles of $30^{\circ}-70^{\circ}$ from the front because the access burr hole was always made $15 \mathrm{~mm}$ lateral to the midline near the coronal suture, ipsilateral to the target.

Standard techniques were used to record and filter the EMG ( $-6 \mathrm{~dB}$ at 20 and $1000 \mathrm{~Hz}$ ) of up to 8 muscles, including hypothenar muscles, flexor digitorum superficialis, flexor carpi ulnaris, biceps, and deltoid. The EMG and microelectrode signals were recorded on tape (bandpass $0-5000 \mathrm{~Hz}$; Model D, Vetter Co., Rebursburg, PA), along with a voice channel to document the instructions being given to the patient and the area being stimulated during the course of somatosensory examination. During the operative procedure, action potentials were discriminated using a level detector, and either the output of the level detector or the raw microelectrode signal was fed into an audio monitor. The activity of neurons whose action potentials could be adequately discriminated was then subjected to visual and auditory examination for evidence of either spontaneous rhythmicity or alteration in the firing pattern during voluntary movement and/or somatosensory stimulation (Lenz et al., 1987). Part of the procedure for characterizing thalamic neurons consisted of observing single unit activity during spontaneous tremor for periods of $15-60 \mathrm{sec}$. During this time, the degree of correlation between thalamic single unit activity and EMG was assessed by watching the oscilloscope screen and listening to the raw microelectrode output or the spike train after discrimination of single unit activity (Lenz et al., 1987). The present study examines the relationship between thalamic single unit activity and EMG activity during well-established tremor, as defined in Results.
Movement artifact is a potentially significant technical problem in the measurement of physiological signals during tremor. The first type of movement artifact, consisting of low-frequency noise in the microelectrode channel, was excluded by the $300 \mathrm{~Hz}$ high-pass filter incorporated into the microelectrode preamplifier circuit. High-frequency transients were occasionally observed, but were excluded by application of the criteria of constant action potential shape during discrimination of single units. A second potential source of movement artifact is related to movement of the microelectrode, producing tremor-synchronous irritation of neurons. The low noise level in the microelectrode recording system permitted discrimination of small action potentials, many of which may have been distant from the microelectrode. When recording from a single cell with a large action potential, the microelectrode was backed off by $25-50 \mu \mathrm{m}$ after isolation of the action potential. Cells with action potentials or firing patterns showing any sign of irritation during recording were excluded from analysis.

Spectral cross-correlation analysis. Tapes of the microelectrode recordings made during the operative procedure were examined postoperatively. All cells analyzed in the present report were located in the region where cells exhibited activity correlated with active movements of the upper extremity. Action potentials were discriminated by standard criteria of size and identified as originating from single units by the criterion of constant shape of the action potential (Lenz et al., 1987). Data were digitized off-line on a CAMAC interface and processed on a microprocessor (Hewlett-Packard 9845). Times of occurrence of spikes were digitized at a clock rate of $1000 \mathrm{~Hz}$. EMG signals were full-wave rectified and filtered $(-6 \mathrm{~dB}$ at $50 \mathrm{~Hz})$ to produce a signal termed the "demodulated EMG." The demodulated EMG was then digitized at $200 \mathrm{~Hz}$, which should produce minimal aliasing because of the filters employed and because the spectral composition of surface EMG in forelimb muscles has a peak at $50 \mathrm{~Hz}$, attenuated to $-20 \mathrm{~dB}$ by 100 $\mathrm{Hz}$ (Sato, 1976). The spike train and 4 EMG channcls were digitized and analyzed in $10.24 \mathrm{sec}$ epochs. The original $2048 \mathrm{bins} / \mathrm{EMG}$ channel were padded with zeros and filtered with a standard second-order finite impulse response (FIR) filter before being decimated to produce 512 data points (Oppenheim and Schafer, 1975).

The spectrum of the spike train was derived by taking the fast Fourier transform (FFT) of an analog equivalent to the spike train (French and Holden, $1971 \mathrm{a}, \mathrm{b}$ ). The equivalent analog signal was computed by representing action potentials in the spike train as delta functions and then digitally filtering this signal with a low-pass rectangular filter whose cutoff frequency was the highest frequency of interest. This filter has an impulse function of form

$$
D(t)=(\sin 2 \pi f t) / 2 \pi f t,
$$

where $f$ is the cutoff frequency of the filter and $t$ is the time relative to the time of occurrence of the spike or delta function. This function is readily approximated to the desired resolution by the standard Taylor series expansion. The average value of the filtered output is then subtracted to minimize leakage due to a large DC or zero-frequency component. This function is then sampled at $2 f$, the Nyquist frequency. The resulting output is indistinguishable from that obtained from any continuous band-limited process. In the present case, the times of occurrence of spikes were measured directly at a clock rate of twice the maximum firing rate of these neurons, so that no significant aliasing occurred during this process. The spike train was filtered with a cutoff frequency of $25 \mathrm{~Hz}$ and sampled at $50 \mathrm{~Hz}$. This resulted in a set of 512 data points, representing the $10.24 \mathrm{sec}$ epoch of the sample.

By definition, the spectra of EMG and thalamic cell activity during tremor exhibit large tremor-frequency peaks. Therefore, it was essential to minimize leakage due to the large low-frequency component introduced by the $10.24 \mathrm{sec}$ rectangular sampling window. We have chosen the 10\% cosine function for a relatively conservative data taper (Bendat and Piersol, 1971). After application of this function, Fourier transforms were taken of the spike and EMG data files by a standard FFT package (Hewlett-Packard Signal Analysis Package). The output of the FFT consisted of raw spectral estimates of the spike train $G s(f)$ and the demodulated EMG $G e(f)$, each containing 512 data points and having a resolution of approximately $0.1 \mathrm{~Hz}$ over a range of DC to $25 \mathrm{~Hz}$. The correctness of these spectra was tested by comparing the results obtained using the present technique with those obtained using a package that employed an autoregressive technique and that had been tested against a wide variety of random signal pairs (Schnider et al., 1986). The spectral cross-correlation function was calculated from the raw spectral estimates in the usual way, as outlined below. To test for correlation between the 
2 signals, the estimated cross-spectrum $G s e(f)$ was calculated from the raw spectral estimates of the 2 signals, $G s(f)$ and $G e(f)$, by equation $(2)$ :

$$
G \operatorname{se}(f)=G s(f) \cdot G e^{*}(f),
$$

where * indicates the complex conjugate.

After computation of the autospectra of the spike train and EMG signals, the autopower spectra were computed according to equation (3):

$$
G x x(f)=G x(f) \cdot G x^{*}(f) .
$$

Spectral estimates derived by this approach have a high degree of variability and hence are inconsistent estimators of the spectrum (Cox and Lewis, 1966; Jenkins and Watts, 1968; Bendat and Piersol, 1971). A consistent estimator of the spectrum can be obtained by smoothing the spectrum through frequency averaging. Groups of $l$ nonoverlapping frequency estimates (equally weighted) are averaged together. If the real and imaginary parts of the spectral estimate are gaussian random variables, then the sum of their squares is distributed as a chi-squared variable with $2 l$ degrees of freedom. The value of $l$ determines the value of the bandwidth $(B)$ of the smoothed spectrum, since $B=l / t$, where $t$ is the observation time (10.24 sec in the present case). Since increasing the value of $l$ decreases the variance at the expense of lowered spectral resolution, the value of $l$ is arbitrarily chosen depending on the desired resolution and the required statistical accuracy of the estimate.

In the present case, the statistical reliability of the smoothed estimate of the cross-correlation spectrum was obtained by evaluation of the coherence function, which is defined by the expression,

$$
K^{2}(f)-|\widehat{\operatorname{Gse}(f)}|^{2} /[\widehat{\operatorname{Gss}(f)} \cdot \widehat{\operatorname{Gee}(f)}],
$$

where the hat $\left({ }^{\wedge}\right)$ indicates a smoothed estimate. The coherence function ranges in value from 0 to 1 . From consideration of the cross-spectrum [eq. (2)], it is obvious that the smoothed spectral estimates must be employed, or the coherence function would be unity for all frequencies. If the 2 signals are identical, then $G s e(f)=G s(f)=G e(f)$ and the coherence equals 1 . If the 2 signals are independent, then $G \operatorname{se}(f)=0$ and the coherence is 0 . If the coherence function is intermediate between 0 and 1 , then 2 possibilities may apply: (1) the relationship between the 2 signals may not be linear; (2) noise or a third process may be influencing one or the other signal. Statistical testing can be performed on the coherence function by a number of different techniques (Benignus, 1969; Lopez da Silva et al., 1973). All spectra in this study were smoothed using $l=8$, so that the probability of 2 signals being linearly related is greater than 0.05 for coherence greater than 0.42 (Benignus, 1969). Since the coherence function is independent of phase, the phase spectrum also provides additional information concerning the relationship between the 2 processes.

The phase spectrum, $\theta \operatorname{se}(f)$ is defined by

$$
\theta \operatorname{se}(f)=\arctan [-\widehat{Q s e(f)} / \overline{I s e}(f)],
$$

where $Q \operatorname{se}(f)$ and $I s e(f)$ are the imaginary and real parts of the smoothed cross-spectral estimates, respectively. Like the squared coherence function, the phase estimate is useful only when preceded by smoothing of the cross-spectrum. The cross-power and phase-spectra functions specify the cross-correlation function in the frequency domain. All spectra except coherence are displayed without a vertical scale and are normalized to the largest component in the spectrum.

\section{Results}

This report includes results for all 161 cclls analyzed for tremorrelated activity in 7 patients with parkinsonian tremor. The activity of thalamic tremor cells was studied in the 3-6 Hz range, since peaks in the EMG spectrum occurred in this range for all data samples recorded during well-established resting tremor. Data segments exhibiting well-established tremor were defined by an EMG autopower spectrum in which low-frequency power $(<1.25 \mathrm{~Hz})$ was less than tremor-frequency power. Only data samples meeting this criterion were included in the present analysis. Correlation of EMG activity with mechanical indices of parkinsonian resting tremor has been previously reported (for example, see Gresty and Findley, 1984) and was not repeated in the present study.
Figure 1 shows an example of the application of spectral crosscorrelation analysis to thalamic single unit and demodulated EMG activities recorded in a patient with parkinsonian tremor. A periodic component is evident on examination of both the spike train and EMG signals. The spike train is composed of bursts of spikes occurring in groups of from 1 to 6 action potentials. Intervals between bursts of spikes are approximately $200 \mathrm{msec}$ in duration and produce the spike autopower spectrum peak at $5.1 \mathrm{~Hz}$. The spike autopower component at tremor frequency is characterized by the $\log _{10}$ spike autopower and signal to noise ratio (SNR). Because all spike trains were converted to an analog signal by the same linear filtering procedure (French and Holden, $1971 \mathrm{a}$ ), the $\log _{10}$ spike autopower provides an absolute, if arbitrary, index of the amount of power occurring at tremor frequency in different cells. We define the SNR of a power spectrum to be the spectral component at tremor frequency divided by the average power of all components occurring in that spectrum. Thus, the SNR indicates the magnitude of the tremor-frequency component relative to the average value of components in the power spectrum.

The raw tracings (Fig. 1 $A$ ) and autopower spectra (Fig. 1C) of the demodulated EMG signals indicate that the relative amount of power occurring at tremor frequency is maximal for finger flexors (EMG 2) and decreases in order through wrist flexors (EMG 3), hypothenars (EMG 1), and biceps (EMG 4). Demodulated EMG autopower spectra of wrist flexors show activity concentrated at tremor frequency and at the first harmonic, while those of hypothenars and biceps show a considerable amount of activity at frequencies adjacent to that of the tremor. The predominance of the tremor frequency activity in muscles of the forearm, but not in biceps, is consistent with the description of parkinsonian tremor as a distal "pill-rolling tremor," most pronounced in muscles of the forearm (Stein and Lee, 1981; Adams and Victor, 1984).

The peak of the thalamic spike autopower spectrum occurs at tremor frequency $(5.1 \mathrm{~Hz})$, as defined by the demodulated EMG autopower spectrum (Fig. 1C). Thus, the cross-power spectra are dominated by the tremor-frequency component, as indicated by the cross-power SNR ranging from 10 to 21 . Since the same spike autospectrum is used to compute each crosspower spectrum, the cross-power SNR indicates the degree to which power in the spike train signal is concentrated at the same frequencies as it is in demodulated EMG signal. The coherence is greater than 0.42 at tremor frequency in the $\mathrm{Sp} \times \mathrm{EMG} 1$, $\mathrm{Sp} \times \mathrm{EMG} 2$, and $\mathrm{Sp} \times \mathrm{EMG} 3$ spectra, and less than 0.42 at almost all other frequencies. These results indicate that tremorfrequency cross-correlation between the spike train and EMG channels 1,2 , and 3 is explained by a linear model to a significant degree.

Examples of the range of magnitude of the tremor-frequency spike autopower are shown in Figure 2. The spike train illustrated in Figure $2 A$ is characterized by intense bursts of activity, approximately 10 action potentials per burst, which occur regularly at a frequency of $3.5 \mathrm{~Hz}$. This spike train gives rise to a high autopower peak, measured in absolute terms by the tremorfrequency $\log _{10}$ spike autopower $(0.87)$, and relative to the average power per spectral component by the tremor-frequency SNR (16.6). The activity of a cell with much weaker tremorfrequency activity is illustrated in Figure $2 C$. The spike train is characterized by single action potentials, with occasional bursts of 2 or 3 action potentials at a frequency of approximately 5 $\mathrm{Hz}$. The $\log _{10}$ spike autopower is 2 orders of magnilude smaller 
A

\section{Spike}

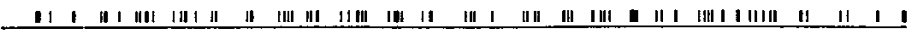
Hypothenar (EMG 1)

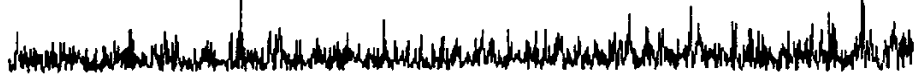
Finger Flexors (EMG 2)

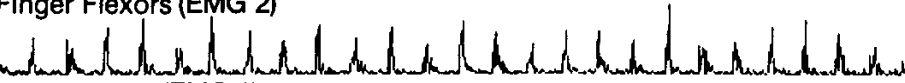

Wrist Flexors (EMG 3)

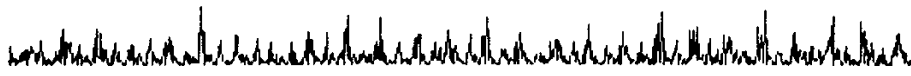
Biceps (EMG 4)

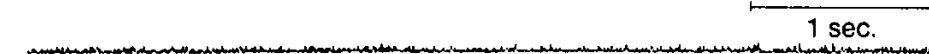

B

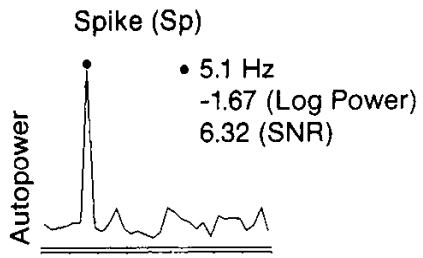

C
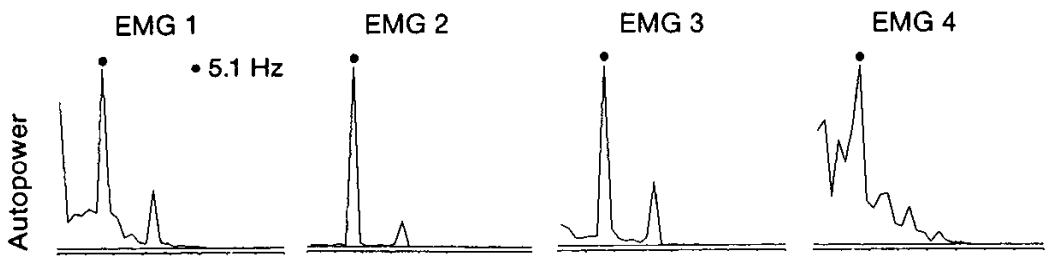

D
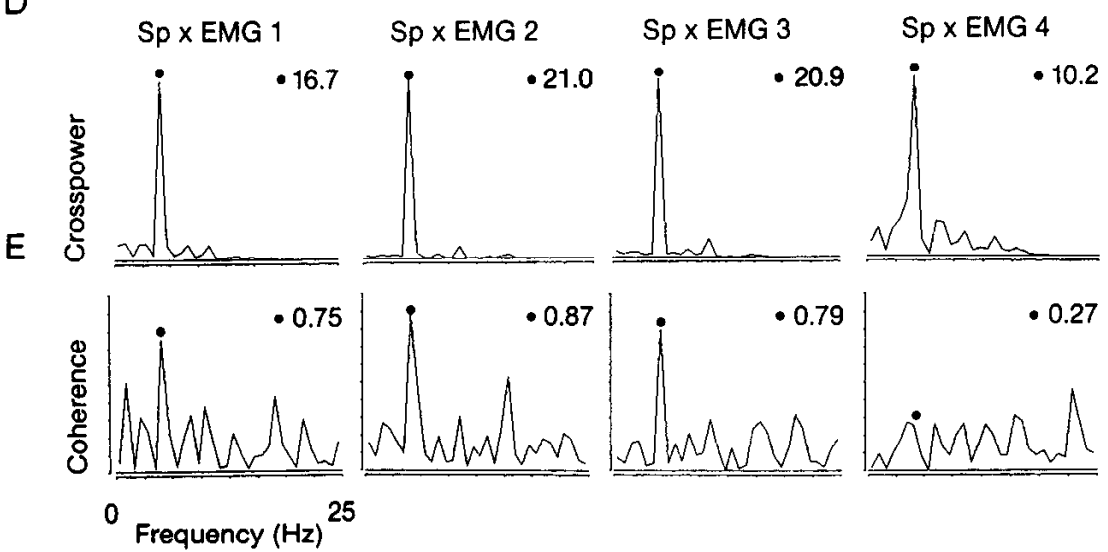

Frequency $(\mathrm{Hz}){ }^{25}$
Figure 1. Simultaneous recording of thalamic single-unit activity and peripheral EMG during tremor in a parkinsonian patient. $A$, Digitized spike train (upper trace) and demodulated EMG channels (lower 4 traces). $B$. Smoothed spike autopower spectrum of the spike train illustrated in $A$. The dot marks the frequency component with maximum power, while numbers displayed to the right of the spectrum indicate, from top to bottom, the frequency, the $\log _{10}$ spike autopower, and spike autopower SNR at tremor frequency. C', Smoothed autopower spectra for each of the demodulated EMG channels (EMG autopower spectrum). The dot indicates the maximum spectral component, which occurs at the same frequency $(5.1 \mathrm{~Hz})$ in the spike and in each EMG autopower spectrum. $D, E$, Cross-power spectra and coherence spectra, respectively, between the spike channel and each demodulated EMG channel. The numerals to the right of these spectra indicate the cross-power SNR $(D)$ and coherence $(E)$ at tremor frequency, determined from the peak of the EMG spectrum $(C)$. for this cell than for the cell illustrated in Figure $2 A$, while the SNR is smaller by a factor of 6 . Figure $2 B$ illustrates 2 spike trains and corresponding autopower spectra that exhibit tremor band peaks of magnitudes intermediate between those of Figure 2, $A$ and $C$. Spike train 1 in Figure $2 B$ is largely composcd of bursts of 2 or 3 action potentials, with a variable interval between bursts. The spectrum is characterized by a broad tremor band peak and a relatively large amount of wideband noise. Note that the peak of tremor cell activity occurs at a lower frequency than that of the demodulated EMG signal, indicated by the dot. The spectrum of spike train 2 in Figure $2 B$ has a large low-frequency component that is attributed to the modulation of tremor-frequency activity that is particularly evident in the first two-thirds of the spike train record. Significant wideband and low-frequency spectral components were often observed and could substantially obscure a prominent frequency component on visual examination of the spike train.
The distribution of $\log _{10}$ spike autopower and SNR at tremor frequencies is illustrated in Figure 3 . Tremor-frequency spike autopower varies by 4 orders of magnitude between different cells in this sample. Although many cells exhibited high SNRs, the distribution of these cells is heavily skewed toward the lower spike autopower SNRs, with the median of the distribution occurring at less than 2 . There may be a bimodal component to the spike autopower SNR histogram, with the 2 peaks centered at 1 and 4 .

During analysis of results from the first 4 patients (64 cells) studied, cross-correlation analysis was carried out with respect to 4 EMG channels, as illustrated in Figure 1. Significant evidence of correlation was found in cross-correlation functions between the spike trains of 12 cells and the 4 different EMG channels (Fig. 4). The results of this analysis indicate that crosspower SNR was maximal for either wrist or finger flexors in each of the data samples studied (Fig. 4A). As assessed by the 
A

Figure 2. Range of magnitudes of spike autopower peaks in the tremor-frequency band. Spike trains and corresponding spike autopower spectra are shown for $\mathbf{4}$ different thalamic cells in $A, B$ (spikes 1 and 2), and $C$. Each spike train in $A$ and $B$ is shown at 2 different time scales, so that the lower spike train corresponds to the interval in the upper spike train indicated by the dots. Time scales for the upper and lower spike trains in $A$ and $B$ are shown below the corresponding traces in $A$. The spike train in $C$ has the same scale as the upper trace in $A$. The dot above each spectrum indicates tremor frequency, as determined from the EMG autopower spectrum corresponding to that spike train. Numbers to the right of each spectrum indicate the $\log _{10}$ spike autopower and spike autopower SNR at tremor frequency, as labeled in $A$.

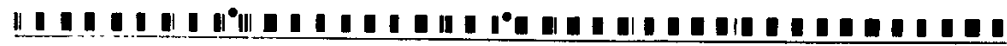
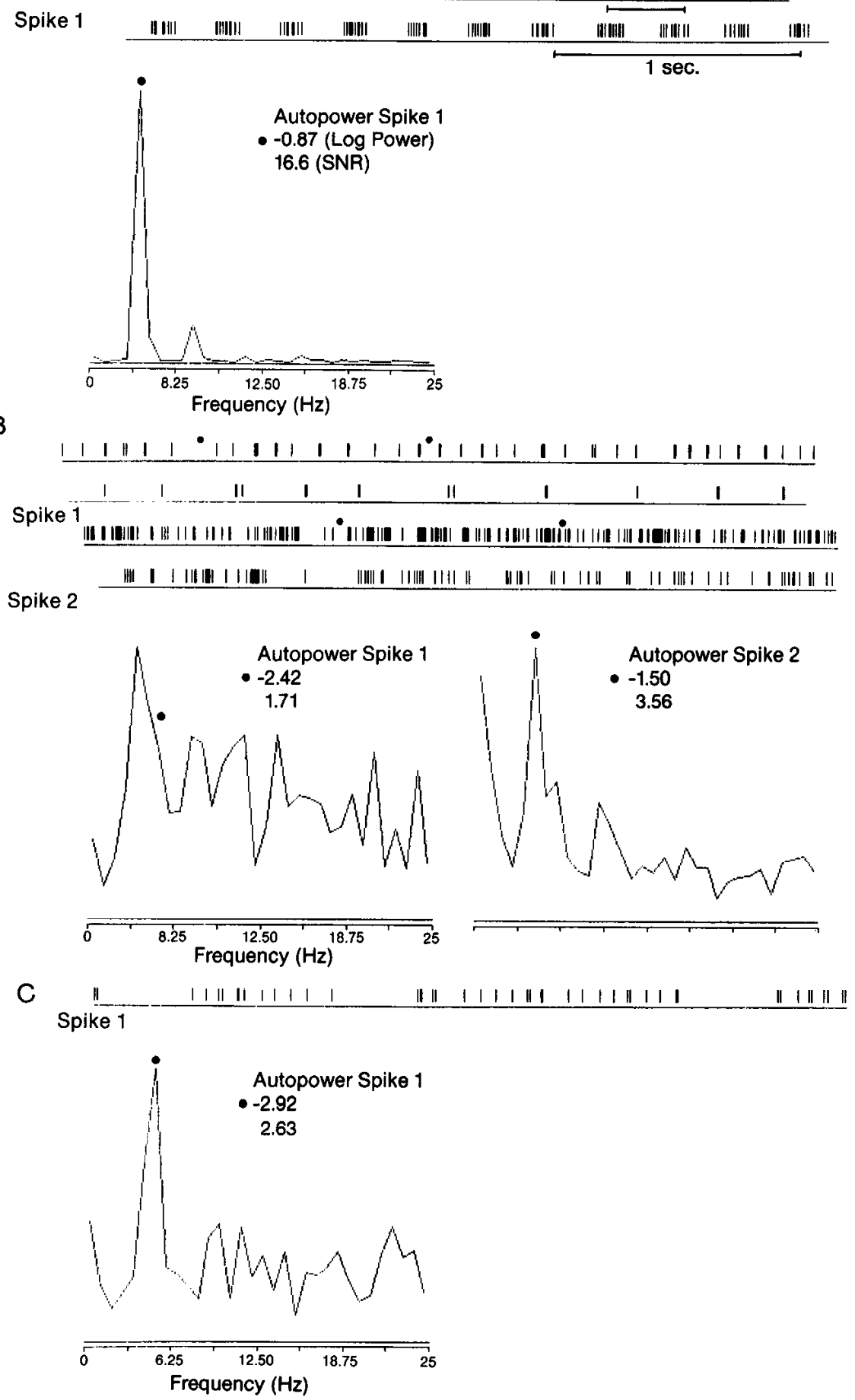

tremor-frequency coherence, significant correlation of the spike train with demodulated EMG activity was never found in hypothenar muscles, wrist flexors, or biceps in the absence of a significant correlation between the spike train and finger flexor demodulated EMG. The coherence values were highest for finger flexors in 9, wrist flexors in 2, and hypothenar muscles in 1 of 12 cases. Therefore, in each data sample the wrist or finger flexor EMG signal shared the highest concentration of power with the thalamic spike train, while finger flexor activity was most consistently correlated with the thalamic spike train as measured by coherence. The EMG channel with the highest coherence has the greatest likelihood of being related to the thalamic spike train in a linear fashion. Since this study was an analysis of the extent to which thalamic spike trains of different cells and EMG activity were linearly related, cross-correlation analysis was performed with finger flexor EMG activity in the remaining 3 patients (97 cells).

Figure 5 illustrates the cross-correlation function between spike trains of 4 thalamic single units and corresponding finger flexor demodulated EMG signals. The spike train illustrated in Figure $5 A$ is characterized by intense bursts of action potentials occurring at the same frequency as demodulated EMG activity 


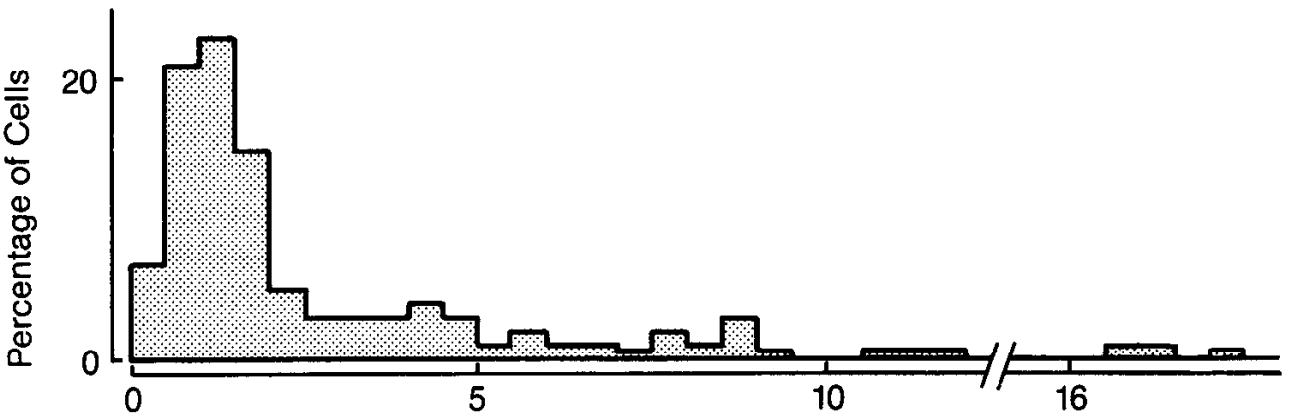

B

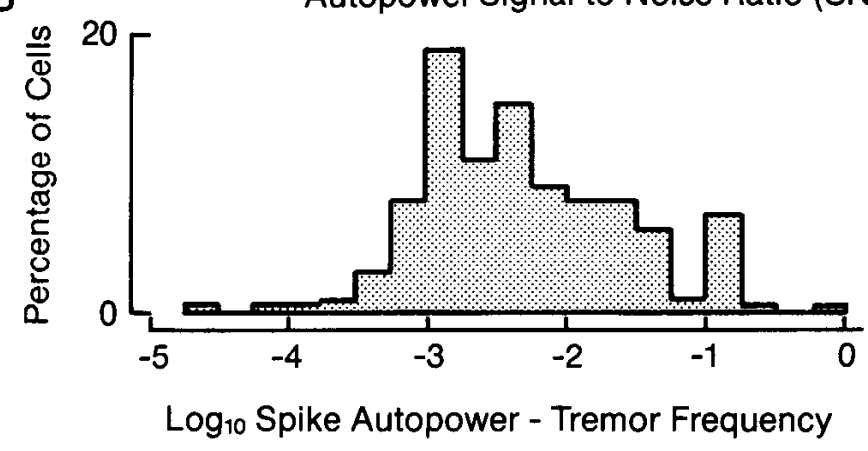

Figure 3. Histograms of the distribution of cells $(n=161)$ by $\log _{10}$ spike autopower $(A)$ and spike autopower $\operatorname{SNR}(B)$. during tremor. The cell's firing pattern is reflected in the autopower spectrum, which is characterized by a high $\log _{10}$ spike autopower and spike autopower SNR at tremor frequency. Tremor-frequency activity is the predominant component in the cross-power spectrum, as indicated by the cross-power SNR. The coherence value indicates a highly significant correlation of the spike train and demodulated EMG signals. The activity of cells illustrated in Figure 5, $B-D$ demonstrates progressively lower spike autopower, spike autopower SNR, and coherence. The difficulty in assessing the degree of correlation from visual examination of the raw data is illustrated in Figure $5 \mathrm{C}$. Although there does appear to be a tremor-frequency component in the spike train, the interval between bursts is highly variable. The spike autopower function indicates that tremor-frequency activity is only marginally greater than the average of all spectral components. The coherence spectrum indicates that the tremorfrequency component of the spike train, although weak, is correlated with the demodulated EMG signal to a significant degree.

Coherence is a function of 2 separate variables, in this case the demodulated EMG signal and the analog equivalent of the spike train. Thus, there is no reason to suppose that coherence should covary with $\log _{10}$ spike autopower or spike autopower SNR. However, the cross-correlation function between the activity of thalamic cells and finger flexor EMG activity illustrated in Figures 1 and 5 suggests that the coherence does covary with both the $\log _{10}$ spike autopower and the spike autopower SNR. The same effect is seen in plots of coherence versus SNR (Fig. $6 A$ ) and $\log _{10}$ spike autopower (Fig. $6 B$ ). Regression analysis verifies the existence of a statistically significant correlation between coherence and SNR $(r=0.53, n=161, p<0.0001)$ and between coherence and $\log _{10}$ spike autopower $(r=0.46, n=$ $161, p<0.0001$ ). Since the spike autopower SNR and $\log _{10}$ spike autopower do vary with coherence, it may be possible to identify a population of cells with prominent tremor-frequency activity that is highly coherent with EMG activity during tremor.
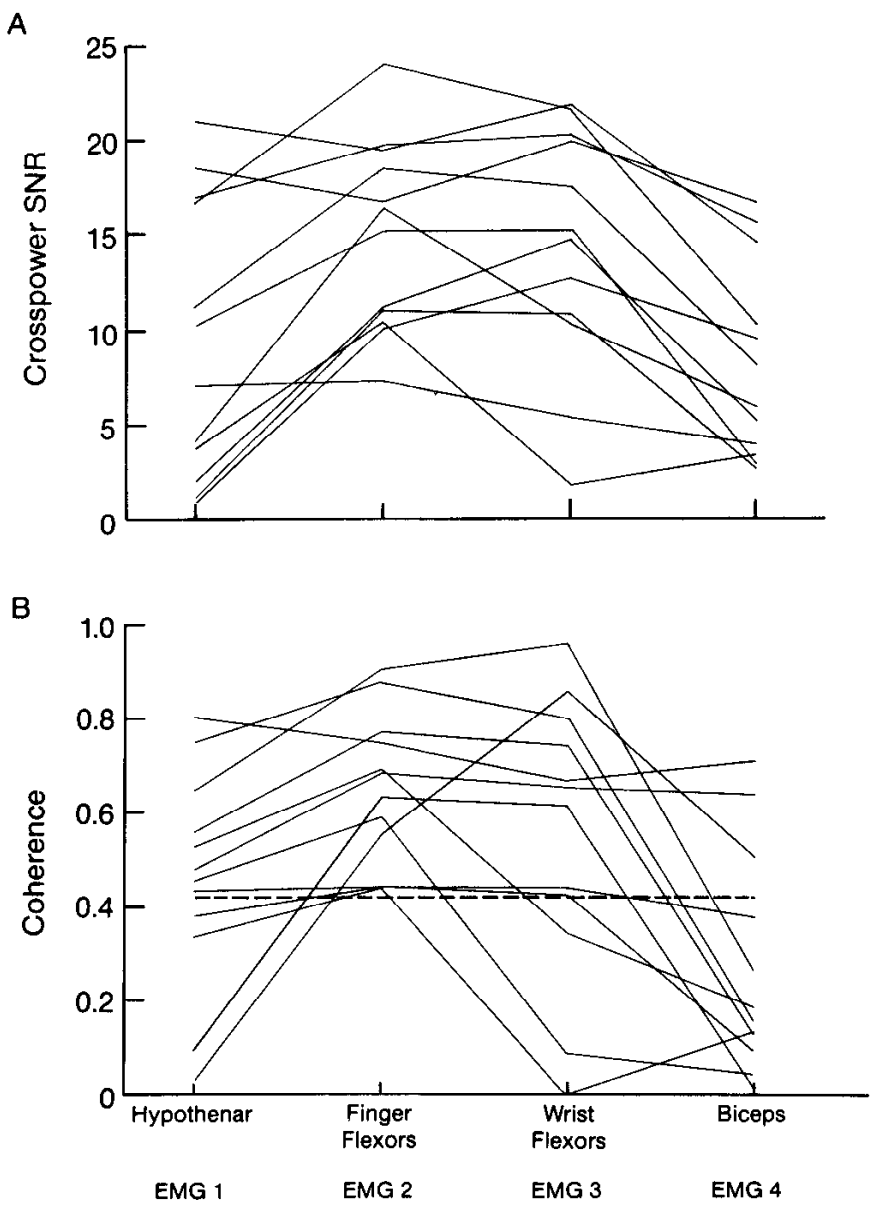

Figure 4. Plots of cross-power and coherence for thalamic spike train signals and demodulated EMG signals recorded from 4 forearm muscles. The cross-power SNR $(A)$ and coherence values $(B)$ are plotted along the vertical axes, and the 4 different demodulated EMG channels are listed along the horizontal axis. Lines join results calculated for the activity of individual thalamic cells. The heavy dashed line in $B$ is at a coherence of 0.42 , the level above which coherence values indicate significant correlation of the thalamic spike and EMG signals. 

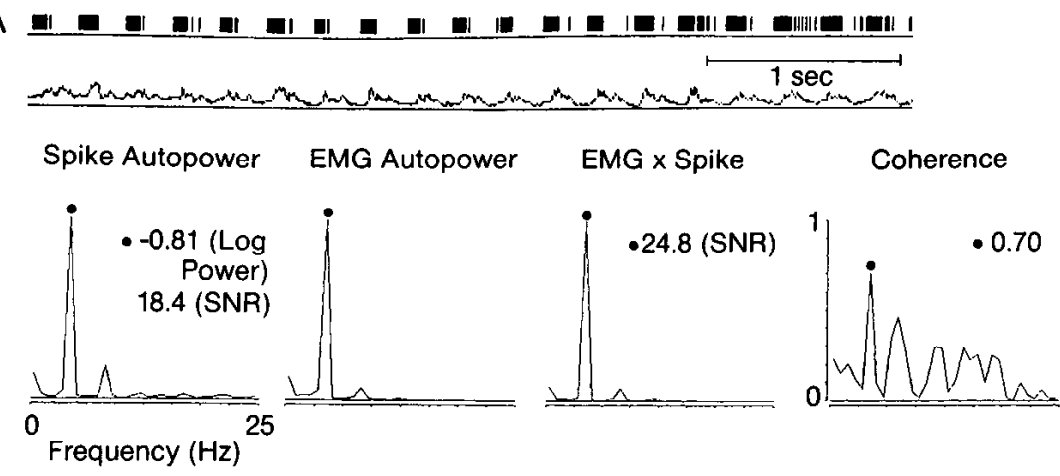

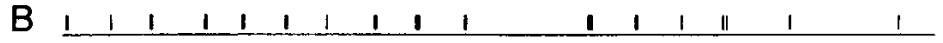

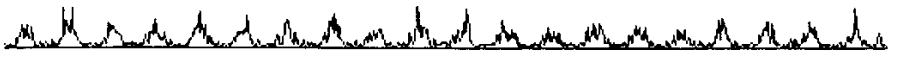

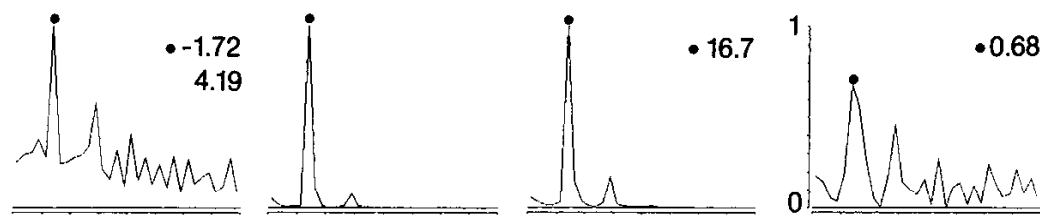

Figure 5. Examples of the cross-correlation function between the spike trains of 4 different thalamic cells $(A-$ $D$ ) and the demodulated EMG signal, recorded in finger flexors. Upper traces, Spike train and demodulated EMG signal. Lower panel shows, from left to right, the spike autopower spectrum, the EMG autopower spectrum, and the cross-power and coherence spectra for that pair of signals. Dots above the spectra indicate tremor frequency, as determined from the EMG autopower spectrum. Numerals to the right of the spectra indicate the tremor-frequency values of the $\log _{10}$ spike autopower and spike autopower SNR in the spike autopower spectrum, cross-power SNR in the cross-power spectrum, and coherence in the coherence spectrum, as labeled in $A$. In the spectra of spike and $E M G$ autopower and of EMG $\times$ Spike cross-power, the vertical axis is normalized to the highest value occurring in the spectrum. The vertical axis of the coherence spectrum is as labeled.

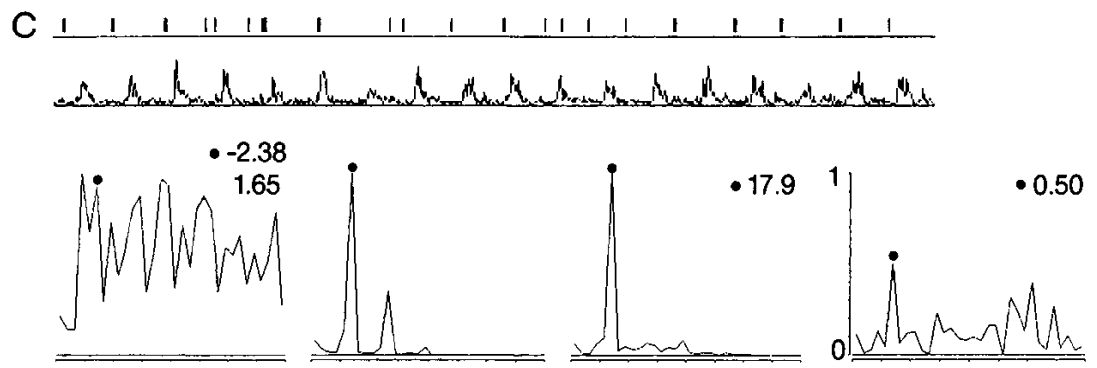

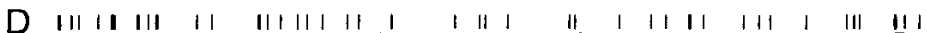

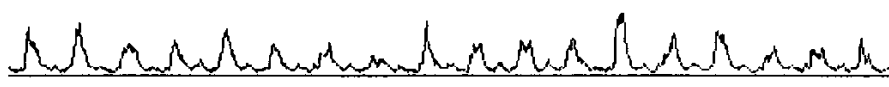
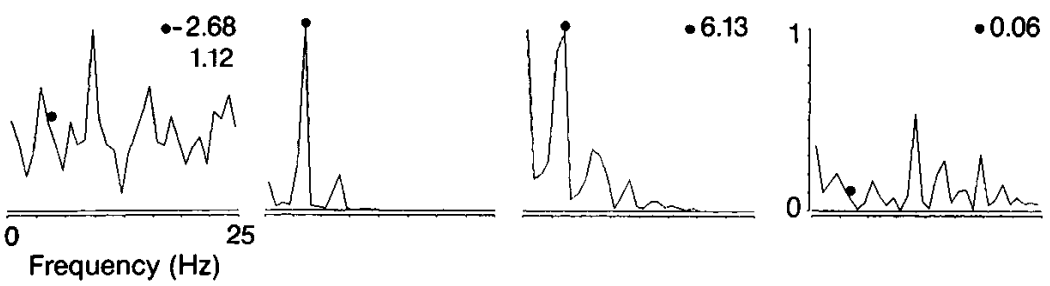

In this analysis, the tremor-frequency component was the largest component of the spike autopower spectrum for all cells in which tremor-frequency spike autopower SNR was greater than 2 (see Figs. 1, 2, and 5 for examples). Furthermore, the distribution of spike autopower values (Fig. $3 A$ ) might be divided into 2 distributions centered at 1 and 4 . On the basis of these 2 observations, we arbitrarily defined tremor cells as cells with a SNR of greater than 2. With this definition, Figure $7 A$ demonstrates that tremor cells have higher coherence than nontremor cells ( $p<0.001$; chi-square). Some of the cells analyzed in this series responded to somatosensory stimulation of cutaneous or deep structures in the arm and so might be correlated with EMG activity on the basis of linear transmission of peripheral somatosensory signals to the thalamus (Yin and Williams, 1976). Figure $7 B$ indicates that correlation between the activity cells responding to somatosensory stimulation and EMG activity during tremor is highly variable. Furthermore, the majority of cells exhibiting spike trains that correlated with EMG activity to a significant degree did not respond to somatosensory stimulation. Thus, mechanisms other than the simple transmission of somatosensory signals must be invoked to explain the correlation of tremor cells with demodulated EMG.

\section{Discussion}

This study demonstrates the presence of a population of cells in the ventral nuclear group of human thalamus that are significantly correlated with the demodulated FMG of muscles in the upper extremity of patients with parkinsonian tremor. Many of these cells are tremor cells by our definition, since they had spike autopower SNRs of greater than 2 and exhibited maximal power at tremor frequency. The $\log _{10}$ spike autopower and spike autopower SNR at tremor frequency varicd significantly with 


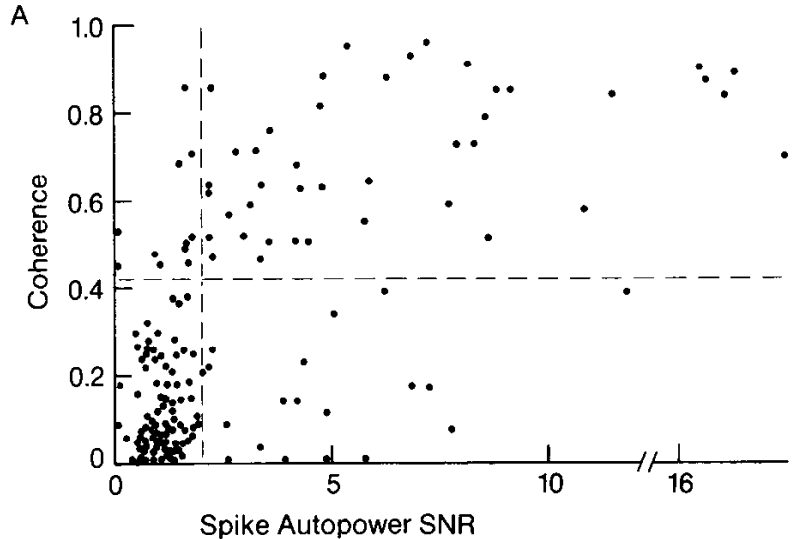

B

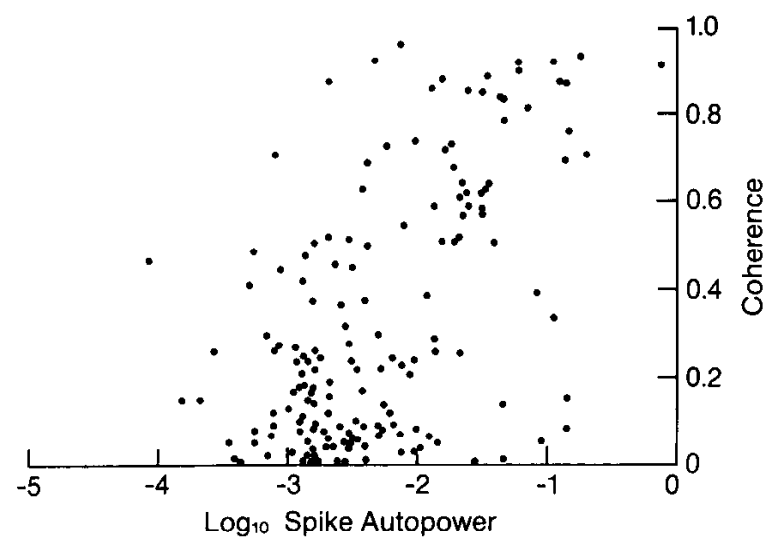

Figure 6. Plots of coherence versus spike autopower SNR $(A)$ and $\log _{10}$ spike autopower $(B)$, all determined at tremor frequency. Axes are as labeled. Dashed lines in $A$ indicate a coherence of 0.42 (horizontal line) and a SNR of 2 (vertical line).

coherence between the spike train and the demodulated EMG signal recorded from finger flexors. Many tremor cells, both responsive and unresponsive to somatosensory stimulation, were correlated with the demodulated EMG signal to a significant degree (Fig. 7). These cells may be involved in the generation of parkinsonian tremor.

\section{Characteristics of tremor cells in human thalamus}

The present study has demonstrated that the spike trains of many thalamic cells in the ventral nuclear group have a major component of power at tremor frequency. Cells with a SNR of greater than 2 , defined as tremor cells, comprised $34 \%$ of all cells studied. This analysis has also demonstrated that a spike train may have a major component of autopower at tremor frequency (spike 2, Fig. 2B), or a significant degree of correlation with EMG activity (Fig. $5 C$ ), even though neither tremor cell activity nor correlation is obvious on visual examination of the spike train. Thus, it is difficult to compare the results of the present study with previous reports in which the activity of tremor cells was studied by visual or auditory examination of the records (Guiot et al., 1962; Gaze et al., 1964; Hardy et al., 1964; Alberts et al., 1965; Jasper and Bertrand, 1966; AlbeFessard et al., 1967; Li and van Buren, 1972; Lucking et al., 1972; Raeva, 1972; Umbach, 1972; Bertrand et al., 1973; Donaldson, 1973; Fukamachi et al., 1973; Hongell et al., 1973; Velasco and Molina-Negro, 1973). Although the degree of correlation cannot be reliably assessed by visual examination of the published raw data (Taylor, 1962; see also Fig. 5C), tremor-
A
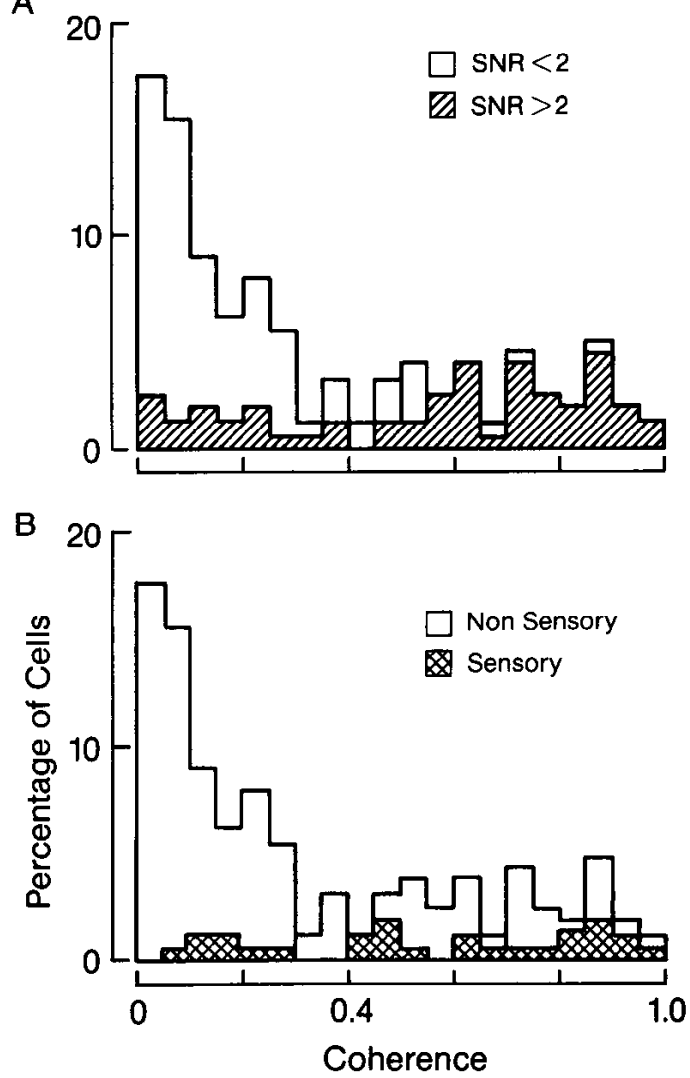

Figure 7. Histogram of coherence between demodulated EMG signal recorded from finger flexors and spike trains of all cells, cells with spike autopower SNR greater than $2(A)$, and cells responding to somatosensory stimulation $(B)$.

frequency activity of many cells in these previous reports (Jasper and Bertrand, 1966; Raeva, 1972, 1986) is similar to that found in the present series.

The tremor cell activity observed in the present study is readily comparable to the results of studies that have employed objective means to assess the rhythmicity of tremor cells in humans (Ohye et al., 1974; Ohye and Albe-Fessard, 1978) and in a primate model of resting tremor produced by lesions in the ventromedial midbrain tegmentum (Ohye and Albe-Fessard, 1978; Lamarre and Joffroy, 1979). In these studies, the time domain autocorrelograms of tremor cell spike trains (Ohye and Albe-Fessard, 1978; Lamarre and Joffroy, 1979) and the peaks of EMG activity during tremor (Lamarre and Joffroy, 1979) are characterized by a large amount of power at similar frequencies. However, the degree of cross-correlation between thalamic tremor cell and EMG activity is difficult to assess because the cross-correlation functions were not evaluated.

In the present study, a large number of cells (34\%) were correlated with EMG activity to a significant degree. Previous studies employing cross-correlation analysis of thalamic and EMG activity during tremor have produced mixed results. Cross-correlation analysis of thalamic field potentials and EMG signals in parkinsonian tremor (Alberts et al., 1965) revealed no significant evidence of correlation between the 2 signals. However, this is a difficult result to interpret, since thalamic spike trains and thalamic slow-wave potentials are usually uncorrelated (F. A. Lenz, H. Kwan, R. Tasker, J. Dostrovsky, and J. Murphy, unpublished observations). Cross-correlograms between tha- 
lamic single units and the peaks of EMG bursts during tremor were computed for 8 cells by Crowell and coworkers (1968). Evidence of correlation between EMG and thalamic activity could not be demonstrated for any of these cells, but was demonstrated when the same analysis was applied to spike trains of 2 tremor cells by Jasper and Bertrand (1966). However, the cross-correlation function may give rise to spurious indicators of correlation in the case of 2 signals occurring at similar frequency (Perkel et al., 1967; Jenkins and Watts, 1968; Glaser and Ruchkin, 1976). In that case, it is essential to subject the cross-correlation function to some type of statistical test, usually by evaluating the coherence function. Although comparisons are hampered by the lack of statistical testing in previous studies, the results of those studies (Alberts et al., 1965; Crowell et al., 1968) are not inconsistent with the present results.

Parkinsonian tremor, like many biological processes, may be highly nonlinear (Milsum, 1966; Gurfinkel and Osovets, 1973; Stein, 1980). We elected to examine the possibility of a linear relationship betwecn thalamic tremor cell and EMG signals by statistical evaluation of the cross-correlation function between these 2 signals. The results identify a population of thalamic cells that are significantly correlated with the $3-6 \mathrm{~Hz}$ component of EMG activity during parkinsonian tremor. In the case of these cells, a significant component of the cross-correlation function at tremor frequency can be explained by a linear process.

\section{Physiologic basis of thalamic tremor cell activity}

It is well known that thalamocortical cells throughout the thalamus fire in bursts at low frequency in intact preparations (Sakakura, 1968; Glenn and Steriade, 1982), intact paralyzed preparations (Filion et al., 1971), and acute preparations with brainstem transections at different levels (Andersen et al., 1969; Steriade et al., 1971, 1985). Self-maintained oscillations are not observed in guinea pig thalamic slice preparation (Jahnsen and Llinas, $1984 \mathrm{a}, \mathrm{b}$ ), although they can be produced in this preparation by current injections. Self-maintained oscillations can be observed in response to stimulation of peripheral (Andersen and Sears, 1964), cortical (Steriade et al., 1983), or intrathalamic structures (Purpura, 1970). These oscillations may be understood in terms of intrathalamic mechanisms (Steriade and Deschenes, 1984).

Bursts of action potentials in thalamocortical cells are synchronized by a powerful IPSP, which may be produced by thalamocortical collaterals either to thalamic inhibitory interneurons (Andersen et al., 1964a, b) or to inhibitory neurons of the thalamic reticular nucleus with axons projecting back to the thalamocortical cells (Steriade and Deschenes, 1984; Steriade et al., 1985). During the rebound from this IPSP, a slow, somatic calcium spike occurs, giving rise to the burst of fast sodium spikes that may activate the same thalamocortical collaterals (Jahnsen and Llinas, 1984a, b; Roy et al., 1984). Thalamic mechanisms may also be involved in the self-maintained oscillations of thalamic neurons that are recorded in primate models of resting tremor.

In monkeys, lesions of the ventromedial midbrain tegmentum produce both a rest tremor resembling parkinsonian tremor (Poirier et al., 1966; Sourkes and Poirier, 1966; Pechadre et al., 1976) and self-maintained oscillation or bursting of thalamic cells (Lamarre and Joffroy, 1970, 1979; Lamarre, 1975). In this preparation, damage to the nigrostriatal tract (Pechadre et al., 1976) and the administration of dopamine antagonists (Bedard et al., 1970; Larochelle et al., 1971) fail to produce tremor unless associated with injury to the cerebellar axons projecting to the red nucleus and thalamus. Therefore, this model of resting tremor may depend upon damage to both substantia nigra and cerebellar structures.

A similar anatomic basis for resting tremor in Parkinson's disease is suggested by studies of parkinsonian patients, which imply that tremor is not produced by isolated impairment of transmission in the nigrostriatal tract. Resting tremor is not commonly seen in the parkinsonian-like syndrome produced by phenothiazines (Marsden et al., 1975). Unlike other manifestations of Parkinson's disease, the severity of tremor is not significantly correlated with reductions of dopamine in caudate or putamen (Bernheimer et al., 1973). However, tremor is significantly correlated with reductions of homovanillic acid, a dopamine metabolite, in putamen and globus pallidus (Bernheimer et al., 1973). Finally, lesions of the globus pallidus, ventral oralis anterior, and ventral oralis posterior relieve parkinsonian rigidity more effectively than they do tremor, while lesions of ventralis intermedius preferentially relieve tremor (Narabayashi, 1968; Narabayashi and Ohye, 1974). Thus, the anatomic substrate of parkinsonian tremor may involve pathways that project to cortex through thalamus (Jenner and Marsden, 1984; DeLong and Alexander, 1986). Pathologic lesions affecting these pathways may potentiate the tendency of thalamocortical cells to oscillate.

The demonstration of correlation between tremor cells and EMG does not allow us to draw any conclusions about the linear mechanism linking the 2 processes. The nature of this mechanism may be revealed by studies of the transfer function linking thalamic single-unit and EMG activity (Schnider et al., 1986) and by examination of the other properties of thalamic tremor cells, particularly their activity in relation to somatosensory stimulation (Lenz et al., 1986a, 1987) and active movement (Lenz et al., 1985).

\section{References}

Adams, R. D., and M. Victor (1984) Principles of Neurology, McGrawHill, New York.

Albe-Fessard, D., G. Arfel, G. Guiot, P. Derome, E. Hertzog, G. Vourch, H. Brown, P. Aleonard, J. de la Herran, and J. C. Trigo (1966) Electrophysiological studies of some deep cerebral structures in man. J. Neurol. Sci. 3: 37-51.

Albe-Fessard, D., G. Arfel, G. Guiot, P. Derome, and G. Guilbaud (1967) Thalamic unit activity in man. Electroencephalogr. Clin. Neurophysiol. (Suppl.) 25: 132-143.

Alberts, W. W., B. Libet, E. W. Wright, and B. Feinstein (1965) Physiological mechanisms of tremor and rigidity in parkinsonism. Confin. Neurol. 26: 318-327.

Andersen, P., and T. A. Sears (1964) The role of inhibition in the phasing of spontaneous thalamocortical discharge. J. Physiol. (I ond.) 173: 459-480.

Andersen, P., C. McBrooks, J. C. Eccles, and T. A. Sears (1964a) The ventrobasal nucleus of thalamus: Potential fields, synaptic transmission and post-synaptic components. J. Physiol. (Lond.) 174: 348-369.

Andersen, P., J. C. Eccles, and T. A. Sears (1964b) The ventrobasal nucleus of thalamus: Types of cells, their responses and their functional organization. J. Physiol. (Lond.) 174: 370-397.

Andersen, P., L. Olsen, K. Skrede, and O. Sveen (1969) Mechanism of thalamo-cortical rhythmic activity with special reference to the motor system. In Third Symposium on Parkinson's Disease, F. J. Gillingham and I. M. L. Donaldson, eds., pp. 112-118, Livingstone, Edinburgh.

Bedard, P., L. Larochelle, L. J. Poirier, and T. L. Sourkes (1970) Reversible effect of $L$-dopa on tremor and catatonia induced by alphamethyl-p-tyrosine. J. Physiol. Pharmacol. 48: 82-84. 
Bendat, J. S., and A. G. Piersol (1971) Random Data: Analysis and Measurement Procedures, Wiley, Toronto.

Benignus, V. A. (1969) Estimation of the coherence spectrum and its confidence interval using the FFT. IEEE Trans. Aud. Electroacoust. 17: 145-150.

Bernheimer, H., W. Birkmayer, O. Hornekiewicz, K. Jellinger, and F. Seitelberger (1973) Brain dopamine and the syndromes of Parkinson and Huntington: Clinical, morphological and neurochemical correlations. J. Neurol. Sci. 20: 415-455.

Bertrand, C., J. Hardy, P. Molina-Negro, and S. N. Martinez (1969) Tremor of attitude. Confin. Neurol. 31: 37-41.

Bertrand, C., S. N. Martinez, J. Hardy, P. Molina-Negro, and F. Velasco (1973) Stereotactic surgery for parkinsonism: Microelectrode recording, stimulation, and oricnted scetions with a lcucotomc. In Progress in Neurological Surgery, vol. 5, H. Krayenbuhl, P. E. Maspes, and W. H. Sweet, eds., pp. 79-112, Karger, Basel.

Cux, D. R., and P. A. W. Lewis (1966) The Statistical Analysis of a Series of Events, Chapman and Hall, London.

Cox, D. R., and P. A. W. Lewis (1970) Multivariate point processes. IBM Research Report RC 3029.

Crowell, R. M., E. Perret, J. Siegfried, and J. P. Villoz (1968) "Movement units" and "tremor phasic units" in the human thalamus. Brain Res. 11: $481-488$.

DeLong, M. R., and G. E. Alexander (1986) Organization of basal ganglia. In Diseases of the Nervous System, A. K. Asbury and G. M. McKhann, eds., pp. 379-393, Saunders, Philadelphia, PA.

Donaldson, I. M. L. (1973) The properties of some human thalamic units. Brain 96: 419-440.

Filion, M., Y. Lamarre, and J. P. Cordeau (1971) Neuronal discharges of the ventrolateral nucleus of the thalamus during sleep and wakefulness in the cat. II. Evoked activity. Exp. Brain Res. 12: 499-508.

French, A. S., and A. V. Holden (1971a) Alias-free sampling of neuronal spike trains. Kybernetik 8: 165-171.

French, A. S., and A. V. Holden (1971b) Semi-on-line implementation of an alias free sampling system for neuronal signals. Comp. Prog. Biomed. 2: 1-7.

Fukamachi, A., C. Ohye, and H. Narabayashi (1973) Delineation of the thalamic nuclei with a microelectrode in stereotaxic surgery for parkinsonism and cerebral palsy. J. Neurosurg. 39: 214-225.

Gaze, R. M., F. J. Gillingham, S. Kalyanaraman, R. W. Porter, A. A. Donaldson, and I. M. L. Donaldson (1964) Microelectrode recordings from the human thalamus. Brain 87: 691-706.

Glaser, E. M., and D. S. Ruchkin (1976) Principles of Neurobiological Signal Analysis, Academic, New York.

Glenn, L. L., and M. Steriade (1982) Discharge rate and excitability of cortically-projccting ncurons in the intralaminar thalamic nuclci during waking and sleep states. J. Neurosci. 2: 1387-1404.

Gresty, M. A., and L. J. Findley (1984) Postural and resting tremors in Parkinson's disease. Adv. Neurol. 40: 361-364.

Guiot, G., J. Hardy, and D. Albe-Fessard (1962) Delimination precise des structures sous-corticales et identification de noyaux thalamiques chez l'homme par l'electrophysiologie stereotaxique. Neurochirurgia 5: 1-18.

Gurfinkel, V. S., and S. M. Osovets (1973) Mechanism of generation of oscillations in the tremor form of parkinsonism. Biofizika $18: 731-$ 790.

Hardy, J., C. Bertrand, and N. Martinez (1964) Activites cellulaires thalamiques liées au tremblement parkinsonien. Neurochirurgie 10: $449-452$.

Hassler, R., F. Mundinger, and T. Riechert (1979) Stereotaxis in Parkinson Syndrome, Springer-Verlag, Berlin.

Hawrylyshyn, P., I. H. Rowe, R. R. Tasker, and L. W. Organ (1976) A computer system for stereotaxic neurosurgery. Comput. Biol. Med. 6: 87-97.

Hongell, A., G. Wallin, and K. E. Hagbarth (1973) Unit activity connected with movement initiation and arousal situations recorded from the ventrolateral nucleus of the human thalamus. Acta Neurol. Scand. 49: 681-698.

Jahnsen, H., and R. Llinas (1984a) Electrophysiological properties of guinea pig thalamic neurons: An in vitro study. J. Physiol. (Lond.) 349: 205-226.

Jahnsen, H., and R. Llinas (1984b) Ionic basis for the electroresponsiveness and oscillatory properties of guinea pig thalamic neurons in vitro. J. Physiol. (Lond.) 349: 227-247.
Jasper, H. H. and G. Bertrand (1966) Thalamic units involved in somatic sensation and voluntary and involuntary movements in man. In The Thalamus, D. P. Purpura and M. D. Yahr, eds., pp. 365-390, Columbia U. P., New York.

Jenkins, G. W., and D. G. Watts (1968) Spectral Analysis, HoldenDay, San Francisco.

Jenner, P., and C. D. Marsden (1984) The neurochemical basis of parkinsonian tremor. In Movement Disorders: Tremor, L. J. Findley and R. Capildeo, eds., pp. 305-321, Macmillan, London.

Kelly, P., and F. J. Gillingham (1980) Long-term results of stereotactic surgery and $l$-dopa therapy in patients with Parkinson's disease: A ten year follow-up study. J. Neurosurg. 53: 332-337.

Lamarre, Y. (1975) Tremorogenic mechanisms in primates. Adv. Neurol. $10: 23-34$.

Lamarre, Y., and A. J. Joffroy (1970) Thalamic unit activity in monkey with experimental tremor. In L-Dopa and Parkinsonism, A. Barbeau and F. H. McDowell, eds., pp. 163-170, Davis, Philadelphia, PA.

Lamarre, Y., and A. J. Joffroy (1979) Experimental tremor in monkey: Activity of thalamic and precentral cortical neurons in the absence of peripheral feedback. Adv. Neurol. 24: 109-122.

Larochelle, L., P. Bedard, L. J. Poirier, and T. L. Sourkes (1971) Correlative neuroanatomical and neuropharmacological study of tremor and catatonia in the monkey. Neuropharmacology 10: 273-288.

Lenz, F. A., R. R. Tasker, H. C. Kwan, S. Schnider, R. Kwong, and J. T. Murphy (1985) Single unit analysis of the ventral tier of lateral thalamic nuclei in patients with parkinsonian tremor. Soc. Neurosci. Abstr. 11: 1164

Lenz, F. A., J. O. Dostrovsky, and R. R. Tasker (1986a) Functional organization of human somatosensory thalamus. Soc. Neurosci. Abstr. 12: 329 .

Lenz, F. A., R. R. Tasker, H. C. Kwan, S. Schnider, R. Kwong, and J. T. Murphy (1986b) Cross-correlation analysis of thalamic "tremor cells" and electromyographic activity in patients with parkinsonian tremor. Appl. Neurophysiol. 48: 305-308.

Lenz, F. A., J. O. Dostrovsky, R. R. Tasker, H. C. Kwan, and J. T. Murphy (1987) Single unit analysis of the human ventral thalamic nuclear group: Somatosensory responses. J. Neurophysiol. (in press)

$\mathrm{Li}, \mathrm{C}-\mathrm{L}$., and J. M. van Buren (1972) Micro-electrode recordings in the brain of man with particular reference to epilepsy and dyskinesia. In Neurophysiology Studied in Man, G. G. Somjen, ed., pp. 49-63, Excerpta Medica, Amsterdam.

Lopez da Silva, F. H., A. Hoeks, T. H. M. T. van Lierop, C. F. Schrijer, and W. Storm van Leeuwen (1973) Confidence intervals of spectra and coherence functions. Their relevance for quantifying thalamocortical relationships. In Beitrage des Symposiums "Die Ouantifizierung des Elektroencephalograms," G. K. Schenk, cd., AEG Tclcfunken, Konstanz, FRG.

Lucking, C. H., A. Struppler, F. Erbel, and W. Reiss (1972) Stereotactic recording from human subthalamic structures. In Neurophysiology Studied in Man, G. G. Somjen, ed., pp. 95-99, Excerpta Medica, Amsterdam.

Marsden, C. D., D. Tarsby, and R. J. Baldessarini (1975) Spontaneous and drug-induced movement disorders in psychotic patients. In Psychiatric Aspects of Neurologic Disease, F. Benson and D. Blumer, eds., pp. 219-265, Grune \& Stratton, New York.

Milsum, J. H. (1966) Biological Control Systems Analysis, McGrawHill, New York.

Narabayashi, H. (1968) Functional differentiation in and around the ventrolateral nucleus of the thalamus based on experience in human stereoencephalotomy. Johns Hopkins Med. J. 122: 295-300.

Narabayashi, H., and C. Ohye (1974) Nucleus ventralis intermedius of the human thalamus. Trans. Am. Neurol. Assoc. 99: 232-233.

Ohye, C. (1982) Depth microelectrode recordings. In Stereotaxy of the Human Brain, G. Schaltenbrand and A. Walker, eds., pp. 372389, Thieme, Stuttgart.

Ohye, C., and D. Albe-Fessard (1978) Rhythmic discharges related to tremor in humans and monkeys. In Abnormal Neuronal Discharges, N. Chalazonitis and M. Boisson, eds., pp. 37-48, Raven, New York.

Ohye, C., Y. Saito, A. Fukamachi, and H. Narabayashi (1974) An analysis of the spontaneous rhythmic and non-rhythmic burst discharges in the human thalamus. J. Neurol. Sci. 22: 245-259.

Oppenheim, A. V., and R. W. Schafer (1975) Digital Signal Processing, Prentice-Hall, Engelwood Cliffs, NJ.

Pechadre, J. C., L. Larochelle, and L. J. Poirier (1976) Parkinsonian akinesia, rigidity and tremor in the monkey: Histopathological and 
neuropharmacological study. J. Neurol. Sci. 28: 147-157.

Perkel, D. H., G. L. Gerstein, and G. P. Moore (1967) Neuronal spike trains and stochastic point processes. 2 . Simultaneous spike trains. Biophys. J. 7: 419-440.

Poirier, L. J., T. L. Sourkes, G. Bouvier, R. Boucher, and S. Carabin (1966) Striatal amines, experimental tremor and the effect of harmaline in the monkey. Brain $89: 37-55$.

Purpura, D. P. (1970) Operations and processes in thalamic and synaptically related neural subsystems. In Neurosciences-Second Study Program, F. O. Schmidt, ed., pp. 458-470, Rockefeller U. P., New York.

Raeva, S. N. (1972) Unit activity of some deep nuclear structures of the human brain during voluntary movements. In Neurophysiology Studied in Man, G. G. Somjen, ed., pp. 64-78, Excerpta Medica, Amsterdam.

Raeva, S. N. (1986) Localization in human thalamus of units triggered during "verbal commands," voluntary movements and tremor. EEG Clin. Neurophysiol. 63: 160-173.

Roy, J. P., M. Clercq, M. Steriade, and M. Deschenes (1984) Electrophysiology of neurons of the lateral thalamic nuclei in cat: Mechanisms of long lasting hyperpolarizations. J. Ncurophysiol. 51:12201235.

Sakakura, H. (1968) Spontaneous and evoked unitary activities of cat lateral geniculate neurons in sleep and wakefulness. Jpn. J. Physiol. 18: $23-42$.

Sato, H. (1976) Power spectral analysis of surface electromyograms during isometric contractions. J. Anthropol. Soc. Nippon 84: 1-14.

Schaltenbrand, G., and P. Bailey (1959) Introduction to Stereotaxis with an Atlas of the Human Brain, Thieme, Stuttgart.

Schnider, S. M., R. H. Kwong, H. C. Kwan, and F. A. Lenz (1986) Detection of feedback in the central nervous sytem of parkinsonian patients. Trans. IEEE Decision Control 25: 291-294.
Scott, R. M., J. A. Brody, and I. S. Cooper (1970) The effect of thalamotomy on the progress of unilateral Parkinson's disease. J. Neurosurg. 32: $286-288$.

Sourkes, T. L., and L. J. Poirier (1966) Neurochemical basis of tremor and other disorders of movement. Can. Med. Assoc. J. 94: 53-60.

Stein, R. B. (1980) Nerve and Muscle, Plenum, New York.

Stcin, R. B., and R. G. Lcc (1981) Tremor and clonus. In Handbook of Physiology: Motor Control, vol. 1, V. B. Brooks, ed., pp. 325-343, American Physiological Society, Bethesda, MD.

Steriade, M., and M. Deschenes (1984) The thalamus as a neuronal oscillator. Brain Res. Rev. 8: 1-63.

Steriade, M., V. Apostol, and G. Oakson (1971) Control of unitary activities in cerebellothalamic pathways during wakefulness and synchronized sleep. J. Neurophysiol. 34: 384-413.

Steriade, M., M. Deschenes, L. Domich, and C. Mulle (1985) Abolition of spindle oscillations in thalamic neurons disconnected from nucleus reticularis thalami. J. Neurophysiol. 54: 1473-1497.

Tasker, R. R., L. W. Organ, and P. A. Hawrylyshyn (1982) The Thalamus and Midbrain of Man. Thomas, Springfield, IL.

Tasker, R. R., J. Siqueira, P. A. Hawrylyshyn, and L. W. Organ (1983) What happened to VIM thalamotomy for Parkinson's disease? $\Lambda \mathrm{ppl}$. Neurophysiol. 46: 68-83.

Taylor, A. (1962) The significance of grouping of motor unit activity. J. Physiol. (Lond.) 162: 259-269.

Umbach, W. (1972) Stereotactic macro- and micro-registration in motor dysfunction and epilepsy. In Neurophysiology Studied in Man, G. G. Somjen, ed., pp. 85-94, Excerpta Medica, Amsterdam.

Velasco, F., and P. Molina-Negro (1973) Electrophysiologic topography of the human diencephalon. J. Neurosurg. 38: 204-214.

Yin, T. C. T., and W. J. Williams (1976) Dynamic response and transfer characteristics of joint neurons in somatosensory thalamus of the cat. J. Neurophysiol. 39: 582-600. 